\title{
A DESCONSIDERAÇÃO DA PERSONALIDADE DAS SOCIEDADES COMERCIAIS.
}

\author{
José Arnaldo de Oliveira ${ }^{1}$ \\ Vilmar Rego Oliveira ${ }^{2}$
}

RESUMO: O presente artigo tem por objetivo tratar sobre o instituto da desconsideração da personalidade das sociedades comerciais, analisando e destacando os elementos necessários para a sua identificação e entendimento.

Além disso, serão abordadas as teorias maior e menor, destacando cada uma das suas fontes do direito, Código de Defesa do Consumidor, Consolidação das Leis do Trabalho, Lei n. 12.529/2011, Legislação Ambiental, Código Civil, Código de Processo Civil e Lei Anticorrupção, bem como as principais especificidades no Direito Português.

Palavras-chave: Desconsideração. Personalidade. Jurídica. Sociedades. Comerciais.

\section{THE DISREGARD OF THE PERSONALITY OF COMMERCIAL COMPANIES.}

\begin{abstract}
The purpose of this article is to deal with the institute of disregarding the personality of commercial companies, analyzing and highlighting the elements necessary for their identification and understanding.

In addition, the major and minor theories will be addressed, highlighting each of its sources of law, Consumer Protection Code, Consolidation of Labor Laws, Law no. 12.529/2011, Environmental Legislation, Civil Code, Code of Civil Procedure and Anti-Corruption Law, as well as the main specificities in Portuguese Law.
\end{abstract}

Keywords/Palabras-claves/Mots-clés: Disregard. Personality. Legal. Societies. Business.

\footnotetext{
1 Mestrando e doutorando em Ciências Jurídicas pela Universidade Autónoma de Lisboa (UAL), Bacharel em Teologia pelo Instituto Bíblico Betel Brasileiro, professor de Grego Antigo, ex-Procurador Federal e atualmente Juiz do Trabalho no Tribunal Regional do Trabalho da $10^{\text {a }}$ Região - Brasil. Endereço de email: vilmarro70@gmail.com.

2 Mestrando e doutorando em Ciências Jurídicas pela Universidade Autónoma de Lisboa (UAL), Bacharel em Ciências Contábeis, pós-graduado em Direito Material, Processual e Constitucional do Trabalho pelas Universidades Tiradentes (UNIT) e Federal da Bahia (UFBA), professor de pós-graduação pelo curso Dom Petrum, professor nos cursos ministrados pela Ematra da 5a Região e atualmente Juiz do Trabalho no Tribunal Regional do Trabalho da 5a Região - Brasil. Endereço de email: arnaldo-oliveira@hotmail.com.
} 


\section{INTRODUÇÃO.}

Com este trabalho, procuraremos fazer um comparativo entre o instituto da desconsideração da personalidade jurídica das sociedades comerciais no Direito Brasileiro e no Direito Português, destacando os pontos que entendemos ser mais relevantes.

Começaremos apresentando os conceitos de alguns estudiosos sobre o que é desconsideração da personalidade jurídica das sociedades comerciais, destacando algumas considerações sobre o referido instituto jurídico.

Também trataremos sobre a pessoa jurídica de direito privado, uma vez que a desconsideração da personalidade jurídica decorre da existência de uma empresa legalmente constituída.

Estudaremos a desconsideração da personalidade jurídica de modo geral, analisando as Teorias Maior e Menor, a primeira com a sua natureza de subjetividade e objetividade, enquanto que verificaremos a questão referente à aplicabilidade jurídica da Teoria Menor.

Considerando a relevância do tema, trataremos da desconsideração inversa e a forma como é caracterizada.

Avançando sobre a matéria, estudaremos sobre a desconsideração da personalidade jurídica das sociedades comerciais no direito brasileiro, destacando cada uma das suas fontes do direito, como o Código de Defesa do Consumidor, Consolidação das Leis do Trabalho, Lei n. 12.529/2011, Direito Ambiental, Código Civil, Código de Processo Civil e Lei Anticorrupção.

Cuidaremos também da análise da desconsideração da personalidade jurídica das sociedades comerciais no Direito Português, demonstrando as suas principais especificidades e normas positivadas atualmente existentes.

Como se observa, a teoria da desconsideração da responsabilidade jurídica das sociedades comerciais é e sempre foi tema relevante em qualquer sociedade, seja no Brasil, Portugal ou em outro país do mundo, face à possibilidade de inobservância do princípio da separação patrimonial entre pessoas físicas e jurídicas, sendo esta a razão e motivação para a sua escolha para a produção deste trabalho.

Com esta pesquisa demonstraremos que países como o Brasil possui legislação pródiga em relação à aplicação da desconsideração da personalidade jurídica, enquanto outros ficam na base da orientação doutrinária e eventualmente jurisprudencial, ou em decorrência de poucas 
leis especiais, dependendo ainda de leis gerais que autorizem a sua aplicação, como é o caso de Portugal.

\section{CONCEITO E REFLEXÕES HISTÓRICAS.}

A desconsideração da personalidade das sociedades comerciais nasceu como uma teoria, desenvolvendo-se com a finalidade principal de prevenir o desvio de finalidade da sociedade empresarial, quer seja em fraude à lei, aos credores ou ao próprio contrato social.

Como se observa, a referida teoria tem como único e exclusivo objetivo responsabilizar a má-fé dos sócios e administradores.

No direito Brasileiro, a primeira conceituação conhecida foi utilizada por Rubens Requião, para quem a citada teoria significa desconsiderar os efeitos da personificação, para atingir a responsabilidade dos sócios, chamada pelo referido doutrinador de teoria da penetração, por adentrar a pessoa jurídica, sem destruí-la, com a finalidade de vincular o sócio e responsabilizá-lo ${ }^{3}$.

O Professor Elpídio Donizetti ${ }^{4}$ conceitua a desconsideração da personalidade jurídica, afirmando que é um instituto excepcional, em que se pretende tornar ineficazes os atos realizados pela sociedade comercial e imputável aos sócios, quando eles forem praticados em descumprimento à função social da empresa.

Caio Mário da Silva Pereira apresenta como conceito de desconsideração da personalidade jurídica como sendo [...] na essência, que em determinada situação fática a Justiça despreza ou “desconsidera” a pessoa jurídica, visando a restaurar uma situação em que chama a responsabilidade e impõe punição a uma pessoa jurídica, que seria autêntico obrigado ou o verdadeiro responsável, em face da lei ou do contrato ${ }^{5}$.

A Doutrina da Desconsideração ou Disregard Doctrine possibilitou retirar, mesmo que momentaneamente, o véu da autonomia patrimonial de uma sociedade legalmente constituída, muito embora anteriormente não fosse possível.

Observa-se que foi a partir do século XIX que começaram a surgir preocupações relativas à má utilização da autonomia patrimonial das sociedades comerciais.

\footnotetext{
3 REQUIÃO, Rubens. Curso de Direito Comercial. 25a ed. São Paulo: Saraiva, 2003. v. 1. p. 377-378.

4 DONIZETTI, Elpídio - Curso Didático de Direito Processual Civil. 19a. edição. São Paulo: Atlas, 2016. ISBN 978-85-970-0386-4. p. 3328.

5 PEREIRA. Caio Mário da Silva. Instituições de direito civil. 22ª . ed. v. I. Rio de Janeiro: Forense. 2007. p. 335.
} 
O nascedouro da desconsideração da personalidade jurídica tem origem nos países que adotam o common law, Reino Unido e Estados Unidos da América, tendo como primeira decisão judicial datada de 1809, no caso Bank of United States $X$ Deveaux, quando o juiz Marshall manteve a jurisdição das cortes federais sobre as corporations. Note-se que a Constituição Americana (art. $3^{\circ}$, seção $2^{\mathrm{a}}$ ) reserva a tais órgãos judiciais as lides entre cidadão de diferentes Estados.

Com esta decisão fixando tal competência, restou por desconsiderar a personalidade jurídica ao fundamento de que não se tratava de uma sociedade, mas de contenda de sócios.

No ano de 1897 ocorreu o segundo caso na Inglaterra, quando o Sr. Aaron Salomon com mais seis membros de sua família fundou uma company, onde cada sócio possuía uma ação, sendo reservadas 20.000 ações a si, integralizando-as com o seu estabelecimento comercial. Além disso, o Sr. Aaron Salomon já exercia a mercancia na forma de firma individual.

Os credores identificaram abalo e esvaziamento do patrimônio do Sr. Aaron Salomon em favor da company e em razão disso, o juízo de primeiro grau declarou fraude com o alcance dos bens do sócio, entretando, a House of Lords, reconhecendo a diferenciação patrimonial entre a companhia e os sócios, reformou a decisão de primeira instância.

Entretanto, foi o alemão Rolf Serick, da Universidade de Tübingen, que nos anos 1950 propôs sistematizar a teoria da desconsideração da personalidade jurídica, apresentando algumas proposições a serem observadas.

Historicamente ficou consagrado que o pressuposto para a desconsideração da personalidade jurídica tem como fundamento a existência de uma pessoa jurídica legalmente constituída que, eventualmente é desconsiderada em benefício dos credores de boa-fé, isso em decorrência de decisão judicial, como forma de exceção ao princípio da separação do patrimônio dos sócios da entidade.

No ano de 1969, a teoria da desconsideração da personalidade jurídica foi trazida ao Brasil pelo doutrinador Rubens Requião, quando foi apresentada em uma conferência realizada na Universidade Federal do Estado do Paraná.

A referida conferência foi realizada em memória do professor Vieira Cavalcanti e denominada de "Sociedades comerciais - Abuso de Direito e Fraude através da Personalidade jurídica (Disregard Doctrine)”, assim concluiu Rubens Requião em sua conferência: 
"Ora diante do abuso de direito e da fraude no uso da personalidade jurídica, o juiz brasileiro tem o direito de indagar, em seu livre convencimento, se há de consagrar a fraude ou o abuso de direito, ou se deve desprezar a personalidade jurídica, para, penetrando em seu âmago, alcançar as pessoas e bens que dentro dela se escondem para fins ilícitos ou abusivos”ø.

Como se observa, o aparecimento da teoria da Disregard Doctrine no Brasil teve forte impacto, uma vez que a doutrina passou a aceitar a possibilidade de flexibilizar o princípio da autonomia patrimonial, até então tido como absoluto para os atos cometidos pelos sócios que contrariassem a lei ou fossem decorrentes de abuso de direito, aplicando-se a desconsideração da personalidade jurídica.

\section{A PESSOA JURÍDICA DE DIREITO PRIVADO.}

O artigo 45 do Código Civil Brasileiro determina que "Começa a existência legal das pessoas jurídicas de direito privado com a inscrição do ato constitutivo no respectivo registro, precedida, quando necessário, de autorização ou aprovação do Poder Executivo, averbando-se no registro todas as alterações por que passar o ato constitutivo".

Assim, verifica-se que a pessoa jurídica possui personalidade jurídica diversa dos sócios que integralizaram a sociedade comercial, sendo também possuidora de patrimônio distinto daqueles que formaram o quadro societário.

O Doutrinador Rubens Requião apresenta excelente conceito de pessoa jurídica:

Entende-se por pessoa jurídica o ente incorpóreo que, como as pessoas físicas, pode ser sujeito de direitos. Não se confundem, assim, as pessoas jurídicas com as pessoas físicas que deram lugar ao seu nascimento; pelo contrário, delas se distanciam, adquirindo patrimônio autônomo e exercendo direitos em nome próprio. Por tal razão, as pessoas jurídicas têm nome particular, como as pessoas físicas, domicílio e nacionalidade; podem estar em juízo, como autoras ou como rés, sem que isso se reflita na pessoa daqueles que a constituíram. Finalmente, têm vida autônoma, muitas vezes superior às das pessoas que as formaram; em alguns casos, a mudança de estado dessas pessoas não

\footnotetext{
6 PEREIRA, Carlos de Brito; REQUIÃO, Rubens; SANTOS, Theophilo de Azeredo. Estudos em memória do Professor Vieira Cavalcanti. Curitiba: [s.n.], 1969. p. 30.
} 
se reflete na estrutura das pessoas jurídicas, podendo, assim, variar as pessoas físicas que lhe deram origem, sem que esse fato incida no seu organismo. É o que acontece com as sociedades institucionais ou de capitais, cujos sócios podem mudar de estado ou ser substituídos sem que se altere a estrutura social ${ }^{7}$.

O professor Fábio Konder Comparato ensina que a personalização da pessoa jurídica tem por objetivo estabelecer centro de interesses autônomos, ou seja, diferentes dos interesses das pessoas que formaram a pessoa jurídica da sociedade comercial. ${ }^{8}$

Esclarecendo a necessidade do surgimento da personalidade jurídica, Ricardo Negrão afirma que:

“A personalidade jurídica é uma ficção jurídica, cuja existência decorre da lei. É evidente que às pessoas jurídicas falta existência biológica, característica própria das pessoas naturais. Entretanto, para efeitos jurídicos e, leia-se, para facilitar a vida em sociedade, concede-se a capacidade para uma entidade puramente legal subsistir e desenvolver-se no mundo jurídico. Sua realidade, portanto é social, concedendo-lhe direitos e obrigações" 9 .

Tratando-se de pessoa com personalidade jurídica e patrimônios próprios, a regra é a de que na hipótese de contrair dívidas, por essas responderá até o montante do seu patrimônio, como normalmente acontece com as pessoas físicas. A personalidade jurídica e a autonomia patrimonial são os limitadores da possibilidade de perda dos bens dos sócios em decorrência de determinado negócio lícito mais arriscado.

Entretanto, caso a sociedade comercial venha a ser utilizada em desacordo com o seu objeto social e ilicitamente, não será possível ao sócio invocar a regra da autonomia patrimonial da pessoa jurídica, fazendo, incidir, portanto, a teoria da desconsideração da personalidade jurídica.

\section{A DESCONSIDERAÇÃO DA PERSONALIDADE JURÍDICA.}

REQUIÃO, Rubens. Curso de Direito Comercial. São Paulo: Forense, 1998. p. 204.

COMPARATO, Fábio Konder; SALOMÃO FILHO, Calixto. O poder de controle da sociedade anônima. $4^{a}$ edição. Rio de Janeiro: Forense, 2005. p. 356.

9 NEGRÃO, Ricardo. Manual de direito comercial e de empresa. 6 a ed. rev. atual. São Paulo: Saraiva, 2008. v. 1. p. 238. 
A DESCONSIDERAÇÃO DA PERSONALIDADE DAS SOCIEDADES COMERCIAIS.

O instituto da desconsideração da personalidade jurídica foi criado para que seja utilizado de forma excepcional, uma vez que normalmente ocorre a preservação da personalidade jurídica das sociedades comerciais que praticaram negócios jurídicos.

A partir de sua utilização, o princípio da autonomia patrimonial, tido como absoluto, passou a possuir exceções nos casos de atos com objetivos abusivos e/ou fraudulentos, cabendo, portanto, a aplicação da teoria da desconsideração da personalidade jurídica, de forma a autorizar a penetração no patrimônio dos sócios e administradores das sociedades.

A desconsideração da personalidade jurídica está dividida em duas teorias, sendo elas: Teoria Maior e Teoria Menor.

Na chamada Teoria Maior, a teoria da desconsideração da personalidade jurídica é aplicada tão somente em casos excepcionais, necessitando que seja evidenciada a existência de fraude, o abuso do direito ou a confusão patrimonial, não ocorrendo de um simples descumprimento de uma obrigação, mas do desvirtuamento da função da personalidade jurídica e do desvio dos fins para o qual a empresa foi criada.

Esta teoria está dividida em Teoria Maior Subjetiva e Teoria Maior Objetiva.

Na Teoria Maior Subjetiva é muito importante verificar a intenção do agente, tendo em vista que para aplicar a desconsideração da personalidade jurídica, necessário se faz a ação dolosa do sócio ou administrador.

Como se observa, a Teoria Maior Subjetiva tem como fundamento a fraude ou abuso do direito com o desvio de finalidade da pessoa jurídica gerada pelo seu mau uso, fugindo a sua finalidade social, o que não pode prevalecer ante a finalidade social da sociedade empresarial.

No que diz respeito ao abuso da personalidade jurídica, embasado no desvio de finalidade, ocorrerá quando a empresa desobedecer ao objeto da empresa, bem como desvirtuar a sua finalidade social, sendo, portanto, possível, a aplicação da teoria da desconsideração para responsabilizar o sócio ou administrador que praticou determinado ato.

Reportando-se a Teoria Maior Objetiva, esta tem como único fundamento a confusão patrimonial para que seja autorizada a aplicação da desconsideração da personalidade jurídica.

Entretanto, é importante ressaltar que mesmo ocorrendo a confusão patrimonial, nem sempre poderá ser aplicada a teoria da desconsideração, pois caberá verificar a existência do pressuposto prejuízo causado a terceiros.

Desse modo, a Teoria Maior Objetiva tem como base para a sua aplicação a comprovação do prejuízo do credor, somada a confusão existente entre os bens da sociedade e seus sócios. 
A denominada Teoria Menor é de muito pouca aplicabilidade, tendo em vista que se baseia tão somente no inadimplemento do devedor, ou seja, é aplicada em casos em que o credor não logre êxito em receber o que lhe é devido ${ }^{10}$.

No ordenamento jurídico brasileiro, a Teoria Menor é aplicada tão somente no que diz respeito aos artigos 28, $\S 5^{\circ}$ do Código de Defesa do Consumidor e art. $4^{\circ}$ da Lei do Meio Ambiente, bem como nas relações trabalhistas.

Temos ainda o que a doutrina denominou de Desconsideração Inversa, que consiste em uma forma de evitar o desvio de bens pessoais para a pessoa jurídica.

Na desconsideração inversa, o sócio transfere os bens pessoais para a sociedade comercial que mantém o controle, continuando a usufruir normalmente do patrimônio, prejudicando os seus credores que não podem executar ou responsabilizar tais bens transferidos.

Ressalte-se que “a teoria da desconsideração inversa só será aplicada para tornar sem efeito a transferência indevida do patrimônio do sócio para a sociedade” ${ }^{11}$.

\section{A DESCONSIDERAÇÃO DA PERSONALIDADE JURÍDICA NO DIREITO BRASILEIRO.}

Para o professor Fábio Ulhoa Coelho, a fraude contra credores ou abuso do direto pode ser praticada através da utilização das sociedades empresárias, efetuando manipulações na constituição da pessoa jurídica, como também realizando a celebração dos mais variados contratos empresariais e/ou operações societárias, como incorporação, fusão e cisão. ${ }^{12}$

No Brasil, o primeiro regramento sobre a matéria ocorreu na Lei $n^{\circ}$ 8.078/90 que trata do Código de Defesa do Consumidor, dispondo na seção IV, mais precisamente no seu artigo 28 o seguinte:

\section{“SEÇÃO V}

Da Desconsideração da Personalidade Jurídica

Art. 28. O juiz poderá desconsiderar a personalidade jurídica da sociedade quando, em detrimento do consumidor, houver abuso de direito, excesso de poder, infração da lei, fato ou ato ilícito ou violação dos estatutos ou contrato social. A desconsideração

\footnotetext{
10 SOUZA. André Pagani. Desconsideração da personalidade jurídica: aspectos processuais. São Paulo: Saraiva, 2009.

11 SOUZA. André Pagani. Desconsideração da personalidade jurídica: aspectos processuais. São Paulo: Saraiva, 2009.

12 COELHO, Fábio Ulhoa. Curso de Direito Comercial: direito de empresa. 16 ${ }^{\mathrm{a}}$ ed. São Paulo: Saraiva, 2012. vol. 2. p. 55.
} 


\section{A DESCONSIDERAÇÃO DA PERSONALIDADE DAS SOCIEDADES COMERCIAIS.}

também será efetivada quando houver falência, estado de insolvência, encerramento ou inatividade da pessoa jurídica provocados por má administração.

$[\ldots]$

$\S 5^{\circ}$ Também poderá ser desconsiderada a pessoa jurídica sempre que sua personalidade for, de alguma forma, obstáculo ao ressarcimento de prejuízos causados aos consumidores.

Depois surgiu a Lei Antitruste, Lei n. 8.884/94, revogada pela atual Lei n. 12.529/11, esta última preservando a hipótese de desconsideração da personalidade jurídica, estabelecendo em seu artigo 34 que “A personalidade jurídica do responsável por infração da ordem econômica poderá ser desconsiderada quando houver da parte deste abuso de direito, excesso de poder, infração da lei, fato ou ato ilícito ou violação dos estatutos ou contrato social”, complementando a hipótese no parágrafo único do referido artigo ao determinar que "a desconsideração também será efetivada quando houver falência, estado de insolvência, encerramento ou inatividade da pessoa jurídica provocados por má administração”.

Em 1998 foi editada a Lei 9.605/98 que trata sobre a responsabilidade por danos causados ao meio ambiente, incluindo-se na legislação brasileira mais uma hipótese de desconsideração da personalidade jurídica prevista no artigo $4^{\circ}$ da referida lei, prevendo expressamente que "Poderá ser desconsiderada a pessoa jurídica sempre que sua personalidade for obstáculo ao ressarcimento de prejuízos causados à qualidade do meio ambiente”.

O Código Civil Brasileiro também resolveu prestigiar a teoria da desconsideração da personalidade jurídica inserindo expressamente na lei, mais precisamente em seu artigo 50 esta hipótese legal, vejamos:

“Em caso de abuso da personalidade jurídica, caracterizado pelo desvio de finalidade, ou pela confusão patrimonial, pode o juiz decidir, a requerimento da parte, ou do Ministério Público quando lhe couber intervir no processo, que os efeitos de certas e determinadas relações de obrigações sejam estendidos aos bens particulares dos administradores ou sócios da pessoa jurídica. 
Como forma de harmonização da legislação já existente, o novo Código de Processo Civil Brasileiro apresenta em seu capítulo IV as regras para a instauração do incidente de desconsideração da personalidade jurídica, uniformizando o procedimento.

\subsection{DESCONSIDERAÇÃO NO CÓDIGO DE DEFESA DO CONSUMIDOR -} CDC.

O Código de Defesa do Consumidor do Brasil trouxe expressamente em seu art. 28 a desconsideração da personalidade jurídica, com o objetivo único de proteger a parte mais fraca da relação jurídica, no caso o consumidor, bem como atender preceito constitucional estabelecido no inciso V do art. 170 da Constituição Federal de 1988 que estabelece os princípios da ordem econômica brasileira.

O referido dispositivo de lei apresenta um rol de possibilidade de aplicação do instituto da desconsideração da personalidade jurídica, permitindo que o Magistrado aplique de ofício, situação diversa do que ocorre no Código Civil, pois neste último depende do requerimento da parte ou do Ministério Público.

Para a professora Thereza Nahas, não há nenhuma discricionariedade do órgão jurisdicional, pois presentes os elementos autorizadores da desconsideração da personalidade jurídica, deve aplicar o quanto estabelece o art. 28 do Código de Defesa do Consumidor. ${ }^{13}$

\subsection{DESCONSIDERAÇÃO NA CONSOLIDAÇÃO DAS LEIS DO TRABALHO} - CLT.

Alguns doutrinadores brasileiros, a exemplo de Suzy Koury, entendem haver previsão direta permissiva da desconsideração da personalidade jurídica na CLT.

"Sempre que uma ou mais empresas, tendo, embora, cada uma delas, personalidade jurídica própria, estiverem sob a direção, controle ou administração de outra, constituindo grupo industrial, comercial ou de qualquer outra atividade econômica, serão, para os efeitos da relação de emprego, solidariamente responsáveis a empresa principal e cada uma das subordinadas” é o que estabelece a Consolidação das Leis do Trabalho - CLT, em seu $\S 2^{\circ}$ do artigo $2^{\circ}$.

Como se observa, a legislação trabalhista brasileira segue também o princípio da proteção à parte mais fraca da relação processual, no caso o empregado.

13 NAHAS, Thereza. Desconsideração da pessoa jurídica: reflexos civis e empresariais no direito do trabalho. $2^{a}$ edição. Rev. e atual. Rio de Janeiro: Elsevier, 2007. p.108 
Além disso, entende-se que a Lei $n^{\circ}$ 8.078/1990 (Código de Defesa do Consumidor), na parte processual, é aplicável ao processo do trabalho, mormente pelo fato de o art. 21 da Lei n ${ }^{0}$ 7.347/1985 (Lei da Ação Civil Pública) determinar a aplicação às ações coletivas e individuais da parte processual do Código de Defesa do Consumidor, no que for compatível. ${ }^{14}$

Não se pode olvidar que por força do art. $8^{\circ}$ da Consolidação das Leis do Trabalho, sendo omissa a legislação trabalhista em relação à responsabilidade trabalhista dos sócios das sociedades comerciais, autorizada fica a aplicação da legislação comum, pelo que se entende perfeitamente possível também a aplicação subsidiária do art. 50 do Código Civil de 2002, possibilitando, o redirecionamento da execução contra o patrimônio dos sócios ou de seus gestores, nas hipóteses previstas em lei.

\subsection{DESCONSIDERAÇÃO NA LEI No 12.529/11.}

A Lei ${ }^{\circ}{ }^{12.529 / 2011 ~ f o i ~ e d i t a d a ~ c o m ~ o ~ o b j e t i v o ~ d e ~ e s t r u t u r a r ~ o ~ S i s t e m a ~ B r a s i l e i r o ~ d e ~}$ Defesa da Concorrência - SBDC, dispondo ainda sobre a prevenção e a repressão às infrações contra a ordem econômica, orientada pelos ditames constitucionais de liberdade de iniciativa, livre concorrência, função social da propriedade, defesa dos consumidores e repressão ao abuso do poder econômico.

Nos termos do art. 34 da referida norma, “a personalidade jurídica do responsável por infração da ordem econômica poderá ser desconsiderada quando houver da parte deste abuso de direito, excesso de poder, infração da lei, fato ou ato ilícito ou violação dos estatutos ou contrato social”, bem como nas hipóteses de falência, estado de insolvência, encerramento ou inatividade da pessoa jurídica provocada por má administração.

A desconsideração prevista na Lei n ${ }^{\circ}$ 12529/2011 está baseada na teoria maior, uma vez que exige a ocorrência de um ato concreto e devidamente comprovado, quando em verdade, deveria ter utilizado a teoria menor.

Quando o legislador condiciona a desconsideração à ocorrência de abuso de direito, excesso de poder, infração da lei, fato ou ato ilícito ou violação dos estatutos ou contrato social, está tratando da teoria maior da desconsideração da personalidade jurídica, situação que é inaceitável para os crimes praticados contra a ordem econômica, uma vez que atinge a coletividade.

14 SARAIVA, Renato; MANFREDINI, Aryanna. Curso de Direito Processual do Trabalho. $13^{\mathrm{a}}$ edição. Salvador: Jus PODIVM, 2016. p. 535. 
Já na teoria menor, bastava a insatisfação da obrigação/crédito do credor para que a desconsideração fosse levada a efeito, sendo esta, a meu ver, a posição mais adequada a ser adotada pelo legislador quando a edição da Lei n ${ }^{\circ}$ 12.529/2011.

\subsection{DESCONSIDERAÇÃO NO DIREITO AMBIENTAL.}

No Direito Ambiental Brasileiro foi editada a Lei $n^{\circ}$ 9.605/98, estabelecendo no seu artigo $3^{\circ}$ que as pessoas jurídicas serão responsabilizadas administrativa, civil e penalmente, nos casos em que a infração seja cometida por decisão de seu representante legal ou contratual, ou de seu órgão colegiado, no interesse ou benefício da sua entidade.

Acrescentou no parágrafo único do citado dispositivo da referida norma legal que a responsabilidade das pessoas jurídicas não exclui a das pessoas físicas, autoras, coautoras ou partícipes do mesmo fato.

Como se observa, a desconsideração da personalidade jurídica restou definida e prevista no parágrafo único do art. $3^{\circ}$ da Lei $n^{\circ}$ 9.605/98 que claramente estabelece que a responsabilidade da pessoa jurídica não exclui a das pessoas físicas, autoras, coautoras ou partícipes do mesmo fato.

Por sua vez, o artigo $4^{\circ}$ do mesmo diploma prevê que poderá ser desconsiderada a pessoa jurídica sempre que sua personalidade for obstáculo ao ressarcimento de prejuízos causados à qualidade do meio ambiente.

Este regramento tem estreita ligação com o princípio da função social da empresa, não sendo aceitável conceder proteção a uma pessoa jurídica que exerce suas atividades sem observar a sustentabilidade e a ponderação entre os princípios do livre exercício da atividade econômica e da defesa do meio ambiente, conforme estabelece a Constituição Federal de 1988, artigo 170, incisos III e VI.

Assim, no Direito Ambiental a penetração no patrimônio dos sócios independe da comprovação de culpa ou atuação com excesso de poder (teoria menor), bastando, tão somente a ocorrência da insuficiência patrimonial da pessoa jurídica obrigada a reparar o prejuízo causado ao meio ambiente.

\subsection{DESCONSIDERAÇÃO NO CÓDIGO CIVIL BRASILEIRO.}

O novo Código Civil Brasileiro em vigor desde 2002 consagrou a desconsideração da personalidade jurídica em seu artigo 50, tendo como parâmetro para a sua aplicação a hipótese 
A DESCONSIDERAÇÃO DA PERSONALIDADE DAS SOCIEDADES COMERCIAIS.

de abuso da personalidade jurídica, ou seja, em razão do desvio de finalidade ou pela confusão patrimonial.

Assim, em caso de abuso da personalidade jurídica, caracterizado pelo desvio de finalidade, ou pela confusão patrimonial, pode o juiz decidir, a requerimento da parte, ou do Ministério Público quando lhe couber intervir no processo, que os efeitos de certas e determinadas relações de obrigações sejam estendidos aos bens particulares dos administradores ou sócios da pessoa jurídica (art. 50 do Código Civil Brasileiro).

No presente caso, para que a desconsideração seja aplicada, devem estar presentes os seguintes requisitos:

a) Sociedade personificada, na qual os sócios tenham responsabilidade limitada;

b) caracterização de fraude ou abuso de direito relacionado à autonomia patrimonial.

c) não se trate de responsabilização direta por ato próprio do sócio ou administrador.

d) manutenção da validade dos demais atos jurídicos, tendo em vista que a desconsideração não tem por objetivo promover a extinção da atividade empresarial.

A Disregard Doctrine prevista no Código Civil de 2002 adota tanto a teoria subjetiva da desconsideração da personalidade jurídica, que requer existência de fraude ou abuso, como a objetiva, esta última bastando a confusão patrimonial entre a sociedade e os sócios.

Cumpre destacar que o desvio de finalidade de uma sociedade comercial restará configurado quando for utilizada para finalidades diferentes daqueles previstos no objeto do contrato social.

A confusão patrimonial decorre da ausência de separação entre o patrimônio social da sociedade e o patrimônio de um ou de todos os sócios.

Entretanto, independentemente de positivação ou não da matéria, a teoria da desconsideração da personalidade jurídica deve ser aplicada pelos juízes e tribunais com o objetivo de aperfeiçoar o direito e impedir a prática de abusos por parte de pessoas jurídicas com objetivo de lesar os credores.

Portanto, existindo sócios de pessoa jurídica que venham a agir de forma fraudulenta e com abuso de direito, não há dúvida que a desconsideração e superação da personalidade jurídica da sociedade é medida que se impõe com toda rigidez. 


\subsection{DESCONSIDERAÇÃO NO CÓDIGO DE PROCESSO CIVIL}

\section{BRASILEIRO.}

Antes do advento do Código de Processo Civil Brasileiro de 2002 a desconsideração da personalidade jurídica ocorria de forma incidental no processo de execução do título executivo extrajudicial e do cumprimento de sentença, exceto em situações excepcionais em que a medida era requerida em ação autônoma.

Entretanto, a partir da vigência do novo Código de Processo Civil, com a redação do artigo 134 foram criadas regras para a instauração do incidente de desconsideração da personalidade jurídica, cabível em todas as fases do processo de conhecimento, no cumprimento de sentença e na execução baseada em título extrajudicial.

Dessa forma, quem tiver interesse em aplicar a desconsideração não precisa aguardar a finalização do processo para pleitear a medida, tanto assim que o $\S 2^{\circ}$ do referido artigo autoriza o requerimento na própria petição inicial, assim dispondo:

“Dispensa-se a instauração do incidente se a desconsideração da personalidade jurídica for requerida na petição inicial, hipótese em que será citado o sócio ou a pessoa jurídica”.

Ademais, nos termos do art. 1.062 do Código de Processo civil o incidente de desconsideração da personalidade jurídica aplica-se também ao processo de competência dos juizados especiais, ampliando-se bastante o instituto.

Observe-se que não obstante a legislação tenha ampliado a aplicação da desconsideração da personalidade jurídica, o objetivo principal do legislador brasileiro foi o de evitar a constrição judicial dos bens do sócio ou da pessoa jurídica, na hipótese de desconsideração inversa, sem qualquer possibilidade de defesa, já que os artigos 134, § $2^{\circ}$ e 135 determinam expressamente a citação dos sócios ou da pessoa jurídica.

Em caso de acolhimento do incidente de desconsideração, nos termos do art. 137 do Código de Processo Civil a alienação ou oneração de bens ocorrida em fraude a execução será declarada ineficaz em relação ao requerente, cabendo ao terceiro adquirente de boa-fé pleitear, em ação de regresso contra o sócio, o ressarcimento dos valores pagos para a aquisição do bem objeto da declaração de desconsideração. 
5.7. DESCONSIDERAÇÃO NA LEI ANTICORRUPÇÃO (Lei no 12.846/2013).

A Lei no 12.846 de $1^{\circ}$ de agosto de 2013, dispõe sobre a responsabilização administrativa e civil de pessoas jurídicas pela prática de atos contra a administração pública, nacional ou estrangeira, fortalecendo os órgãos de controle e aumentando o rigor das sanções impostas às empresas em razão de crimes de corrupção, incluindo-se a hipótese de fraude em procedimentos licitatórios, traz previsão expressa de desconsideração da personalidade jurídica.

O referido diploma legal é aplicável às sociedades empresárias e às sociedades simples, personificadas ou não, não importando a forma de organização ou modelo societário adotado. Aplica-se a referida lei ainda as fundações, associações de entidades ou pessoas, ou sociedades estrangeiras, que possua sede, filial ou representação no Brasil, constituída de fato ou de direito, mesmo que por prazo determinado.

$\mathrm{O}$ art. $2^{\circ}$ da Lei $\mathrm{n}^{0} 12.846$ determina que as pessoas jurídicas serão responsabilizadas objetivamente, nos âmbitos administrativo e civil, pelos atos lesivos previstos nesta Lei praticados em seu interesse ou benefício, exclusivo ou não, subsistindo a responsabilidade da pessoa jurídica na hipótese de alteração contratual, transformação, incorporação, fusão ou cisão societária (art. $4^{\circ}$.).

De outra banda o art. $3^{\circ}$ afirma que a responsabilização da pessoa jurídica não exclui a responsabilidade individual de seus dirigentes ou administradores ou de qualquer pessoa natural, autora, coautora ou partícipe do ato ilícito, na medida da sua culpabilidade, independentemente da responsabilização da pessoa jurídica.

No capítulo que trata do processo administrativo de responsabilização foi inserida no artigo 14 a determinação de que a personalidade jurídica poderá ser desconsiderada sempre que utilizada com abuso do direito para facilitar, encobrir ou dissimular a prática dos atos ilícitos previstos nesta Lei ou para provocar confusão patrimonial, sendo estendidos todos os efeitos das sanções aplicadas à pessoa jurídica aos seus administradores e sócios com poderes de administração, observados o contraditório e a ampla defesa.

Assim, pela primeira vez uma legislação brasileira trouxe previsão legal de desconsideração da personalidade jurídica em sede administrativa, em razão dos ilícitos estabelecidos pelo art. $5^{\circ}$ da Lei $\mathrm{n}^{0} 12.846$, desde que configurado abuso de direito pela pessoa jurídica ou para provocar confusão patrimonial. 


\section{A DESCONSIDERAÇÃO DA PERSONALIDADE JURÍDICA NO DIREITO}

\section{PORTUGUÊS.}

A legislação portuguesa não é vasta em regras que estabeleçam a teoria da desconsideração da personalidade jurídica.

Entretanto, verificamos que o antigo Código Comercial Português, mais precisamente o art. $186^{\circ}$, § $1^{\circ}$ e o art. $40^{\circ}$ da L.S.Q., legislações revogadas pelo atual Código das Sociedades Comerciais de Portugal (Decreto-Lei $n^{0}$ 262/86) tratavam sobre a matéria e merecem a informação neste trabalho.

O Decreto-Lei $n^{0} 422 / 83$ apresenta no seu art. $14^{\circ}$ uma norma que podemos considerar capaz de estabelecer a desconsideração da personalidade jurídica, quando equipara um grupo de empresas a uma única empresa, assim estabelecendo:

"Para efeitos de aplicação deste artigo, é equiparado a empresa o grupo de empresas, entendendo-se como tal o conjunto de empresas que, embora juridicamente distintas, se comportam concertadamente no mercado, em virtude de vínculos de interdependência ou subordinação de carácter financeiro, contratual, directivo ou outro”.

O atual Código das Sociedades Comerciais, atualmente em vigor através do DecretoLei $n^{0}$ 262/86 apresenta regras específicas de desconsideração da personalidade jurídica para as sociedades comerciais (artigos $84^{\circ}$., 501 . e $502^{\circ}$ ), conforme veremos a seguir.

O art. $84^{\circ}$ do referido código determina que "Sem prejuízo da aplicação do disposto no artigo anterior e também do disposto quanto a sociedades coligadas, se for declarada falida uma sociedade reduzida a um único sócio, este responde ilimitadamente pelas obrigações sociais contraídas no período posterior à concentração das quotas ou das acções, contanto que se prove que nesse período não foram observados os preceitos da lei que estabelecem a afectação do património da sociedade ao cumprimento das respectivas obrigações”.

O artigo 501. ${ }^{\circ}$ trata da responsabilidade para com os credores da sociedade subordinada estabelecendo que a sociedade diretora é responsável pelas obrigações da sociedade subordinada, constituídas antes ou depois da celebração do contrato de subordinação, até ao termo deste, atribuindo ainda que responsabilidade da sociedade diretora não pode ser exigida antes de decorridos 30 dias sobre a constituição em mora da sociedade subordinada, muito 


\section{A DESCONSIDERAÇÃO DA PERSONALIDADE DAS SOCIEDADES COMERCIAIS.}

menos mover-se execução contra a sociedade diretora com base em título exequível contra a sociedade subordinada.

No que diz respeito ao artigo $502^{\circ}$, observamos que este dispositivo trata da responsabilidade por perdas da sociedade subordinada, determinando que esta tenha o direito de exigir que a sociedade diretora compense as perdas anuais que, por qualquer razão, se verifiquem durante a vigência do contrato de subordinação, sempre que estas não forem compensadas pelas reservas constituídas durante o mesmo período. Além disso, a responsabilidade prevista só é exigível após o termo do contrato de subordinação, mas torna-se exigível durante a vigência do contrato, se a sociedade subordinada for declarada falida.

Como se observa, as regras anteriormente mencionadas estão no rol de exceção previstas na lei portuguesa para o princípio separação patrimonial, de forma a privilegiar a desconsideração da personalidade jurídica face à necessidade de proteger a boa-fé dos credores.

Não obstante, constata-se que as normas atualmente existentes no direito Português, são regras específicas e não gerais, comportando e aceitando apenas uma quantidade pequena e específica de casos ocorridos na seara jurídica.

Em relação à jurisprudência portuguesa, importante apresentar sumário de acórdão do Tribunal da Relação de Coimbra - TRC, no processo nº 943/10.8TTLRA.C1, da lavra do Relator FELIZARDO PAIVA, datado de 03/07/2013, deixando muito claro o entendimento que:

"I - A desconsideração ou levantamento da personalidade colectiva surgiu na doutrina e, posteriormente, na jurisprudência como meio de cercear formas abusivas de actuação, que ponham em risco a harmonia e a credibilidade do sistema.

II - No fundamental, ela traduz-se numa delimitação negativa da personalidade colectiva por exigência do sistema ou "exprime situações nas quais, mercê dos vectores sistemáticos concretamente mais poderosos, as normas que firmam a personalidade colectiva são substituídas por outras normas.

III - O recurso a esse instituto é possível quando ocorram situações de responsabilidade civil assentes em princípios gerais ou em normas de protecção, nomeadamente dos credores, ou em situações de abuso de direito e não exista outro fundamento legal que invalide a conduta do sócio ou da sociedade que se pretende atacar, ou seja, a desconsideração tem carácter subsidiário. 
IV - De entre elas avultam a confusão ou promiscuidade entre as esferas jurídicas de duas ou mais pessoas, normalmente entre a sociedade e os seus sócios (ainda que não tenha de ser obrigatoriamente assim); a subcapitalização da sociedade, por insuficiência de recursos patrimoniais necessários para concretizar o objecto social e prosseguir a sua actividade; e as relações de domínio grupal.

V - Em todas estas situações verifica-se que a personalidade colectiva é usada de modo ilícito ou abusivo para prejudicar terceiros, existindo uma utilização contrária a normas ou princípios gerais, incluindo a ética dos negócios.

VI - A desconsideração tem de envolver sempre um juízo de reprovação sobre a conduta do agente, ou seja, envolve sempre a formulação de um juízo de censura e deve revelar-se ilícita, havendo que verificar se ocorre uma postura de fraude à lei ou de abuso de direito.”

Do mesmo modo e com idêntica consistência também o Acórdão do Tribunal da Relação do Porto - TRP, com decisão da lavra do Relator HENRIQUE ARAÚJO de 25/10/2005, processo $n^{\circ} 0524260$ asseverando que:

“I- Quando a personalidade colectiva seja usada de modo ilícito ou abusivo para prejudicar terceiros, é possível proceder ao levantamento da personalidade colectiva.

II- Esta abrange o abuso da personalidade e o abuso da responsabilidade limitada.

III- A desconsideração da personalidade jurídica só deverá ser invocado quando inexistir outro fundamento legal que invalide a conduta do sócio ou da sociedade que se pretende atacar.”

\section{CONCLUSÃO.}

O estudo apresentado neste trabalho abordou a teoria da desconsideração da personalidade jurídica, demonstrando as suas especificidades, conceito, reflexões históricas, bem como tratou da formação da pessoa jurídica de direito privado e do princípio da separação patrimonial entre pessoas físicas e jurídicas.

Verificamos como se formou a teoria da desconsideração da personalidade jurídica, com o objetivo de conter objetivos abusivos e/ou fraudulentos, tratando da sua classificação em Teoria Maior subjetiva e objetiva e Teoria Menor, explicando a forma de enquadramento em cada uma delas. 
Em relação à referida teoria, demonstramos ainda a possibilidade da desconsideração inversa de modo a evitar que o sócio efetue transferências indevidas para o patrimônio da sociedade com o objetivo de fraudar os credores.

Avançando os estudos, constatamos que a desconsideração da personalidade jurídica teve seu ingresso no direito brasileiro através da nossa doutrina, especificamente do professor Rubens Requião que em 1969 trouxe para o Brasil a doutrina apresentada em um congresso realizado pela Universidade Federal do Paraná.

Constatamos que a primeira lei brasileira a determinar a aplicação da teoria da desconsideração da personalidade jurídica foi o art. 28 do Código de Defesa do Consumidor, abrindo o início de um novo tempo para inserção deste regramento em diversas outras leis, como o próprio Código Civil Brasileiro, Lei no 12.529/2011 que regulas o sistema brasileiro de defesa da concorrência, Lei n 9.605/98 referente ao direito ambiental, Código de Processo Civil Brasileiro e Lei no 12.846/2013 que dispõe sobre o sistema anticorrupção.

Na seara trabalhista, estudamos o regramento próprio estabelecido na Consolidação das Leis do Trabalho do Brasil onde alguns doutrinadores entendem ser uma espécie de desconsideração da personalidade jurídica, enquanto a corrente majoritária comunga de forma diversa, muito embora a norma trabalhista autorize a utilização do direito comum de forma subsidiária, a exemplo do Código de Defesa do Consumidor e do Código Civil.

No direito português, verificamos que a teoria da desconsideração da personalidade jurídica é reconhecida pela doutrina e jurisprudência dos tribunais portugueses, entretanto, observamos que a legislação de Portugal trata da matéria apenas em algumas leis específicas, diferentemente do que ocorre no Brasil onde temos previsão legal em diversas normas, inclusive no Código Civil e Código de Processo Civil.

Por fim, observamos que entre as normas portuguesas que estabelecem a possibilidade de aplicação da teoria da desconsideração da personalidade jurídica está o Decreto-Lei noㅜ 262/86, tratando-se, portanto, do Código das Sociedades Comerciais de Portugal.

\section{REFERÊNCIAS BIBLIOGRÁFICAS E JURISPRUDÊNCIA.}

ARAÚJO, Henrique relat. - Acórdão do Tribunal de Relação do Porto com o número JTRP00038440, de 25 de outubro de 2005 [Em linha]. [Consult. 26 Jan. 2017]. Disponível em http://www.dgsi.pt/jtrp.nsf/0/b3b73b76a8c252ad802570b300563fa9?OpenDocument.

BRASIL. Constituição (1988). Constituição da República Federativa do Brasil. Brasília, DF: Senado Federal, 1988. 
CÓDIGO de Processo Civil Brasileiro: Lei $n^{0}$ 13.105, de 16 de março de 2015. Publicado no Diário Oficial da União de 17.03.2015.

COELHO, Fábio Ulhoa. Curso de Direito Comercial: direito de empresa. 16a edição. São Paulo: Saraiva, 2012. vol. 2.

COMPARATO, Fábio Konder; SALOMÃO FILHO, Calixto. O poder de controle da sociedade anônima. $4^{\mathrm{a}}$ edição. Rio de Janeiro: Forense, 2005.

CORDEIRO, Pedro. A desconsideração da personalidade jurídica das sociedades comerciais. $3^{\text {a }}$. edição. Lisboa: Universidade Lusíada Editora, 2008.

CORREIA, Miguel J. A. Pupo. Direito Comercial. Direito da Empresa. 12ª edição. Lisboa: Ediforum, 2011.

Decreto-Lei n no 5.452, de 01 de maio de 1943. Aprovou a Consolidação das Leis do Trabalho. Diário Oficial da República Federativa do Brasil, Brasília, DF, 10/11/1943.

DIDIER JR., Fredie. Coleção Novo CPC. Parte Geral. 2a edição. Salvador: Jus PODIVM, 2016.

DONIZETTI, Elpídio - Curso Didático de Direito Processual Civil. 19a edição. São Paulo: Atlas, 2016.

Lei $n^{0} 8.078$ de 11 de setembro de 1990. Dispõe sobre a proteção do consumidor. Diário Oficial da República Federativa do Brasil, Brasília, DF, 12/09/1990.

Lei $n^{\circ}$ 9.605/98, de 12 de fevereiro de 1998. Dispõe sobre as sanções penais e administrativas derivadas de condutas e atividades lesivas ao meio ambiente. Diário Oficial da República Federativa do Brasil, Brasília, DF, 13/02/1998.

Lei $\mathrm{n}^{\circ}$ 10.406, de 10 de janeiro de 2002. Institui o Código Civil. Diário Oficial da República Federativa do Brasil, Brasília, DF, 11/01/2002.

NAHAS, Thereza. Desconsideração da pessoa jurídica: reflexos civis e empresariais no direito do trabalho. 2a edição. Rev. e atual. Rio de Janeiro: Elsevier, 2007.

NEGRÃO, Ricardo. Manual de direito comercial e de empresa. 6a edição. rev. atual. São Paulo: Saraiva, 2008. v. 1.

PAIVA, Felizardo relat. - Acórdão do Tribunal de Relação de Coimbra com o número 943/10.8TTLRA.C1, de 03 de julho de 2013 [Em linha]. [Consult. 26 Jan. 2017]. Disponível em http://www.dgsi.pt/jtrc.nsf/8fe0e606d8f56b22802576c0005637dc/cd3d74692f29d01080257bad00396235?Open $\underline{\text { Document }}$

PEREIRA. Caio Mário da Silva. Instituições de direito civil. $22^{\mathrm{a}}$ edição. v. I. Rio de Janeiro: Forense. 2007.

PEREIRA, Carlos de Brito; REQUIÃO, Rubens; SANTOS, Theophilo de Azeredo. Estudos em memória do Professor Vieira Cavalcanti. Curitiba: [s.n.], 1969.

PIRES, Antônio Cecílio Moreira. A desconsideração da personalidade jurídica nas contratações públicas. São Paulo: Atlas, 2014.

REQUIÃO, Rubens. Curso de Direito Comercial. 25a edição. São Paulo: Saraiva, 2003. v. 1.

RIBEIRO, Maria de Fátima. Sociedades Comerciais (Responsabilidade). Porto: Universidade Católica Editora, 2015. 
A DESCONSIDERAÇÃO DA PERSONALIDADE DAS SOCIEDADES COMERCIAIS.

SARAIVA, Renato; MANFREDINI, Aryanna. Curso de Direito Processual do Trabalho. $13^{\mathrm{a}}$ edição. Salvador: Jus PODIVM, 2016.

SOUZA. André Pagani. Desconsideração da personalidade jurídica: aspectos processuais. São Paulo: Saraiva, 2009.

TRIBUNAL de Justiça de Minas Gerais - Agravo de Instrumento - Cv 1.0338.05.037512-4/001, Relator (a): Des.(a) Washington Ferreira, $1^{\text {a }}$ CÂMARA CÍVEL, julgamento em 02/02/2016, publicação da súmula em $16 / 02 / 2016$.

TRIBUNAL de Justiça do Paraná - Ação Civil de Improbidade Administrativa 9493758 PR 949375-8 Acórdão - Data de publicação: 21/02/2013.

TRIBUNAL de Justiça do Paraná - 10ª C. Cível - AI - 1387388-8 - Curitiba - Rel.: Luiz Lopes - Unânime - J. 22.10.2015

TRIBUNAL Regional do Trabalho da Bahia - Processo 0001089-10.2014.5.05.0291 RecOrd, Origem

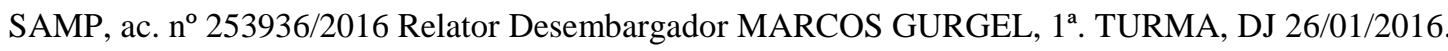

